\title{
Zebrafish Larvae as a Behavioral Model in Neuropharmacology
}

\author{
Ram Manohar Basnet ${ }^{1, *}$, Daniela Zizioli ${ }^{1}$, Somrat Taweedet ${ }^{1}$, Dario Finazzi ${ }^{1,2} \mathbb{D}$ and \\ Maurizio Memo ${ }^{1}$ \\ 1 Department of Molecular and Translational Medicine, University of Brescia, 25123 Brescia, Italy; \\ daniela.zizioli@unibs.it (D.Z.); s.taweedet@unibs.it (S.T.); dario.finazzi@unibs.it (D.F.); \\ maurizio.memo@unibs.it (M.M.) \\ 2 Clinical Chemistry Laboratory, ASST-Spedali Civili di Brescia, 25123 Brescia, Italy \\ * Correspondence: r.basnet@studenti.unibs.it or rmb.basnet@gmail.com
}

Received: 12 February 2019; Accepted: 22 March 2019; Published: 26 March 2019

\begin{abstract}
Zebrafish larvae show a clear and distinct pattern of swimming in response to light and dark conditions, following the development of a swim bladder at 4 days post fertilization. This swimming behavior is increasingly employed in the screening of neuroactive drugs. The recent emergence of high-throughput techniques for the automatic tracking of zebrafish larvae has further allowed an objective and efficient way of finding subtle behavioral changes that could go unnoticed during manual observations. This review highlights the use of zebrafish larvae as a high-throughput behavioral model for the screening of neuroactive compounds. We describe, in brief, the behavior repertoire of zebrafish larvae. Then, we focus on the utilization of light-dark locomotion test in identifying and screening of neuroactive compounds.
\end{abstract}

Keywords: zebrafish larvae; behavior; neuropharmacology; high-throughput screening; neuroactive drugs; light-dark test

\section{Introduction}

There are many practical advantages of using zebrafish as an animal model such as external fertilization, optical transparency, small size, high fecundity, and low housing cost [1-3]. The zebrafish genome has been completely sequenced and the majority of zebrafish genes are common to humans with $84 \%$ of genes known to be associated with human disease having zebrafish counterparts [4]. Zebrafish also have a high homology to mammalian morphology and biology making them an attractive animal model in studying human disorders [5]. The validity of zebrafish models is not only due to the closeness of zebrafish morphologically and genetically, but also behaviorally. In particular, zebrafish exhibit a wide range of complex behaviors including social, anxiety, learning and memory, and defensiveness that may be useful for modeling neurological and psychiatric diseases [6-10].

The mammalian and zebrafish behavioral paradigms are in close parallel suggesting the evolutionarily conserved nature of many behaviors across species [3,5,11]. Despite neuroanatomical differences between the mammals and teleosts, evidence shows homologous functions in several key zebrafish brain areas [12-15]. The recent emergence of high-throughput tracking of zebrafish embryos and larvae has further bolstered the behavior research in the zebrafish field, making the research more objective, replicable, and efficient. Increased research in zebrafish has led to the characterization of a wide range of behaviors at different developmental stages. A comprehensive catalog of zebrafish describing more than one hundred behaviors of embryonic larvae and adult zebrafish is already available [16]. 
In this review, we will concentrate on the behavior of zebrafish larvae. Zebrafish larvae show similarity to adult zebrafish and other vertebrates in key behaviors utilized in neuropharmacology such as anxiety and stress [17]. The small size, optical transparency, rapid generation time, easy manipulation, permeability to small molecules, and cost effectiveness are some general advantages of larval zebrafish over the adult zebrafish. Lately, with the advent in technology, the use of zebrafish larvae is gaining momentum in the field of behavioral research, particularly in neuropharmacology and circuit neuroscience $[18,19]$. For instance, a large-scale high-throughput behavioral analysis, which could screen thousands of compounds in a day, is possible using zebrafish larvae $[19,20]$. Similarly, it is also possible to visualize/monitor/track the neuronal activity of zebrafish larvae while the larvae are engaged in a behavior [16,19-21]. Besides the technical aspects, the use of zebrafish larvae follows the principles of 3Rs (Replacement, Reduction, Refinement) [21], in which there is an effort to reduce the use of adult animals in biomedical research [22]. However, the use of zebrafish larvae in behavior research suffers from some limitations. For instance, the behavior repertoire of zebrafish larvae is not as sophisticated as that of adult zebrafish and other vertebrates [23]. Various factors such as the size and color of individual wells affect the behavior in zebrafish larvae [23]. Overall, the use of larvae has some limitations but the advantages as described above make them an attractive model in the field of biomedical research.

It is well known that zebrafish larvae are sensitive to a variety of stimulus modalities, including touch, olfaction, chemosensation, audition, vestibular inputs, heat, and vision [24]. Among the behaviors, locomotion or swimming in zebrafish larvae is increasingly gaining attention in neuropharmacology. Swimming starts in zebrafish at $48-72 \mathrm{~h}$ post fertilization (hpf) following hatching although zebrafish embryos as early as $27 \mathrm{hpf}$, when dechorionated, can swim in response to touch [25]. After hatching, the newly hatched larvae show burst swimming, which then matures to beat and glide swimming by 4 days post fertilization (dpf) [26-28]. Zebrafish larvae after $4 \mathrm{dpf}$, when exposed to an alternating light and dark stimuli, create a pattern of increased movement in the dark followed by resting state in the light [29]. This behavior has been increasingly utilized in the high-throughput screening of various neuroactive drugs recently. This review focuses on the light and dark stimuli-induced locomotor behavior of zebrafish larvae as a behavioral model to study neuroactive compounds. We describe, in brief, the behavior repertoire of zebrafish larvae and then discuss the utility and importance of light and dark stimuli-induced locomotor behavior in identifying neuroactive compounds. In addition, we also discuss the recent progress made in behavioral research in the context of the emergence of various high-throughput techniques for the automatic tracking of larvae.

\section{Connection Between Brain and Behavior}

Zebrafish provide a platform among vertebrate model systems to study the connection between different brain areas with behavior. The structural organization and cellular morphology of the zebrafish brain is very similar to that of other vertebrates, including chickens, rats, and humans $[5,30,31]$. Many structures, such as retina, olfactory bulb, cerebellum, and spinal cord, are similar in architecture in zebrafish and other vertebrates [18]. Besides the structural homology, the zebrafish brain is similar to humans and rodents with respect to neurochemistry [5]. The zebrafish brain contains all the major components required for neurotransmission, such as neurotransmitter receptors, transporters, and enzymes of synthesis and metabolism. It also has the same neurotransmitter system as that of higher vertebrates such as GABA, glutamate, dopamine, noradrenaline, serotonin, histamine, and acetylcholine [5,32]. Among the various neurochemical pathways, several pathways involved in the modulation of behavior in zebrafish have been well characterized. For example, the ascending midbrain dopaminergic pathway has been well characterized [33] with a number of putative functional homologues with their connection and projections. Dopaminergic neurons are detected at $18-19 \mathrm{hpf}$ in the ventral diencephalon which ascend in the striatum and resemble a mammalian nigrostriatal system [32]. 
Also, many brain regions associated with human disease show molecular and structural homology in zebrafish [34]. For example, the habenula and amygdala in zebrafish are involved in the control of affective behaviors, as in humans and rodents [5]. The habenula regulates the release of serotonin and dopamine and is evolutionarily highly conserved [10]. The hyperactivation of habenula leads to similar conditions such as depression and stress-related behaviors in both mammals and zebrafish [5]. Habenular hyperactivation causes depression in humans and rodents and induces stress-related behaviors in zebrafish. This demonstrates the similarity in brain function between zebrafish and mammals [5]. However, one difference with mammals is the lack of neocortex in zebrafish-the primary area controlling executive functions commonly disrupted in psychiatric disease. Recently, it has been shown that the smaller vertebrate brain such as in zebrafish, despite lacking neocortex, is capable of cognitive processing and even complex decision making [35].

In addition to structural homology, zebrafish larvae have an added advantage of visualizing the neural circuits while they perform a certain behavior. The larval brain at $5 \mathrm{dpf}$ is very compact at $1.5 \mathrm{~mm}$ in length and $500 \mu \mathrm{m}$ in thickness, thus making virtually all the neurons accessible to in vivo imaging $[15,18,36,37]$. The visualization of brain activity through imaging methods is an important step to understand how the brain contributes to normal and abnormal behavior [18]. The emergence of circuit neuroscience has provided opportunity to study the neural circuits involved in various behaviors, such as prey capture, optokinetic response, and optomotor response in zebrafish larvae [18].

\section{Behavior Repertoire in Zebrafish Larvae}

The increased characterization of behaviors in zebrafish larvae, which are comparable to the adult zebrafish and rodents, have increased the scope of their utility in the field of neuroscience $[5,16]$. The larval stage of zebrafish starts from $72 \mathrm{hpf}$ (from protruding mouth stage) and lasts until they undergo metamorphosis to become juvenile [38] at approximately one month. During this period, zebrafish possess a plethora of behaviors which could be analyzed automatically or manually and quantitatively or qualitatively. The zebrafish behaviors have been exploited in diverse research areas such as ethology, toxicology, pharmacology, neuroscience, and genetics [39-45]. In neuropharmacology, the behavior repertoire of zebrafish larvae has been utilized in a multipurpose way-for identifying new drugs with central nervous system (CNS) effect, for repurposing of drugs with CNS effects, for identifying drugs for various psychiatric illnesses such as anxiety and mood disorders, for the study of drugs affecting sleep disorders, and for identifying the therapeutic and target specificity of newer compounds [19,46-48]. The commonly exploited behaviors of zebrafish larvae are described below.

\subsection{Thigmotaxis}

The tendency of an animal to move in contact with a vertical surface is called thigmotaxis [49]. In thigmotaxis, an animal avoids the center of an arena and moves towards the edge or periphery of a novel environment such as a wall [50]. Therefore, it is also known as wall-hugging behavior. It is a valid index of anxiety $[50,51]$ and is evolutionarily conserved across different species, such as fish, rodents, and humans [52,53]. Zebrafish larvae with thigmotaxis prefer to stay near the wall of multi-well plates or Petri dishes. They show thigmotaxis as early as $5 \mathrm{dpf}$ [53]. Anxiolytic drugs, such as diazepam, and anxiogenic drugs, such as caffeine and pentylenetetrazole, have been shown to attenuate and enhance thigmotaxis in larval zebrafish [53-55]. Therefore, thigmotaxis is crucial in studying anxiogenic and anxiolytic drugs.

\subsection{Startle Response}

The startle response is a sensorimotor response universal in animals in which they show a rapid and protective response to sudden, strong, and abrupt stimulus such as loud sounds and unexpected touch [56]. Zebrafish larvae show a sudden increase in the velocity and acceleration of movement/swimming in response to visual, tactile, or acoustic stimuli [51]. The startle response is important as it provides the status of the integration of sensory and motor stimulus. The tactile 
startle response is present as early as $2 \mathrm{dpf}$ and it can be induced by touching the head or tail of the zebrafish larvae [51]. The visual startle response develops by $3 \mathrm{dpf}$. In the visual startle response, larval zebrafish are placed inside a closed chamber equipped with an infrared light and camera. After a brief period of adaptation, they are presented with transient white light and the resulting movement is documented to measure the visual startle response. The test to measure the visual startle response is also called the visual motor response test [57]. Zebrafish larvae show the acoustic startle response after $5 \mathrm{dpf}$ [58]. They show a startle response to sound frequencies of greater than $200 \mathrm{~Hz}$ [59]. The startle response is vital in the study of neuropsychiatric diseases of humans as an abnormal startle response signals a broader neurological problem [56]. Study of the startle response plays a major part in neuropharmacological research as some drugs that alter prepulse inhibition could be used for the treatment of diseases such as schizophrenia [60].

\subsection{Optokinetic Response}

The optokinetic response is the stereotyped eye movement in response to movement in the field of vision. It helps in the stabilization of images in the retina. It is also important in maintaining visual acuity, which in turn helps animals in spatial orientation, hunting for prey, and escaping from predators [61]. Zebrafish larvae develop optokinetic response by $4 \mathrm{dpf}$ [62], following which it can be precisely measured [63]. The optokinetic response is evoked in zebrafish larvae by movements in the form of moving graphics on a liquid crystal display (LCD) monitor [17] or a striped black and white rotating drum [61]. Many drugs acting on the central nervous system, such as sedatives, anti-psychotics, and anti-depressants, modulate eye movements. Therefore, the optokinetic response can be used as a complementary test for characterizing the central nervous system effects of drugs [64].

\subsection{Optomotor Response}

When zebrafish larvae are presented with moving stripes, they tend to swim in the same direction as the moving stripes. This visual-motor behavior of zebrafish is called the optomotor response. Zebrafish larvae start displaying this behavior at $6 \mathrm{dpf}[65,66]$. This response can be used to test visual function of the zebrafish larvae and testing of a compound at an early stage of discovery using a low volume of the compound [67].

\subsection{Habituation}

Habituation is a non-associative form of learning in which a repeated stimulus leads to an attenuated response $[58,68]$. It is evolutionarily conserved and present in a wide range of species from invertebrates, such as Aplysia and Drosophila, to vertebrates such as rodents [58]. It serves as a mechanism by which the nervous system filters irrelevant stimuli. Zebrafish larvae at $6 \mathrm{dpf}$ have been demonstrated to show habituation. Defective habituation is associated with several neuropsychiatric diseases such as schizophrenia and attention deficit hyperactivity dis//Rihel, 2010 \#75\\order (ADHD) [69]. Habituation studies could be used for the high-throughput screening of new compounds with specific effects on non-associative learning [69].

\subsection{Prey Capture}

Once the zebrafish embryos are hatched, they initiate swimming and catch any potential food, also called prey capture. This behavior develops in zebrafish larvae as early as $4 \mathrm{dpf}$ [70]. Prey capture is a complex locomotor behavior and the larvae use vision along with fine axial motor control to find and follow the prey [71,72]. It can be elicited in zebrafish larvae by placing a small air bubble in the test arena. The reaction of zebrafish larvae to the air bubble involves recognition, approach, decision making, and capturing [70]. Prey capture is crucial for the survival of the zebrafish larvae post absorption of yolk sac. As prey capture involves a decision making process, which is directly related to cognition [70], it could be used for the screening of drugs affecting cognition. 


\subsection{Sleep/Awake Behavior}

The sleep/awake pattern of zebrafish is similar to that of humans [73,74]. Zebrafish larvae from 6 to $10 \mathrm{dpf}$ have been used for sleep research. Similar to human infants, larval zebrafish at 6-10 dpf showed a higher percentage of sleep compared to the adult zebrafish [73]. The sleep/awake pattern of zebrafish larvae has been exploited for studying drugs affecting the nervous system [75-78]. Sigurgeirsson et al. characterized the effects of modafinil—a narcoleptic drug-on sleep-wake cycles in larval zebrafish. Using $24 \mathrm{~h}$ behavioral monitoring, the effects of modafinil-a drug used for the treatment of narcolepsy - on sleep/awake length and structure of bout distributions were evaluated both in day and night. Modafinil had similar effects in larval zebrafish as it does in mammals in the sleep/awake cycles [77]. Wang et al. showed that tracking of the normal movement behavior of zebrafish larvae using a video-tracking system can be utilized for determining the effect of anti-depressant drugs [78]. Similarly, Rihel et al. also performed a detailed analysis of multiple behavioral parameters using an automated rest/awake behavioral assay in zebrafish larvae for the screening of 5648 compounds. This assay was able to identify 547 compounds which significantly altered the larval behavior as compared to controls [75]. Therefore, the zebrafish rest/awake cycle could potentially be utilized in identifying or prescreening of the neuroactive drugs.

\subsection{Locomotor Behavior}

Locomotion is integral for the survival of animals. Zebrafish larvae show mature swimming at 4-5 dpf [79] following the development of a swim bladder. Locomotion in zebrafish is a complex behavior produced by the activity of various neurons-reticulospinal neurons of the brain stem along with descending vestibulospinal or neuromodulatory projections [80]. All these pathways are evolutionarily conserved among the vertebrates [80]. In addition, the neurotransmitter systems present in the zebrafish are also common to that of other vertebrates [81]. The precision analysis of locomotion in zebrafish larvae with high-throughput methods could provide accurate information needed for the screening and identification of neuroactive compounds. There are various locomotor behavioral assays used for identifying neuroactive drugs [17]. Among them is the light-dark locomotion test in which the locomotor activity and movement pattern of zebrafish larvae are analyzed via high-throughput automatic tracking by placing them in multi-well plates inside a closed chamber and exposing them to alternating light and dark conditions following a period of acclimatization, as shown in Figure 1. The distance travelled and the pattern of movement of zebrafish larvae in each of the conditions is evaluated for understanding the neurobehavioral effects. Zebrafish larvae show a specific pattern of movement when exposed to alternating light and dark conditions [82]. The movement pattern depends on the transitions-light to dark transition and dark to light transition. The light-dark transition increases locomotor activity whereas the dark-light transition decreases locomotor activity in zebrafish larvae. The increased levels of locomotor activities upon the light-dark transition are attributed to the increased stress/anxiety level in zebrafish larvae [83-85]. These locomotor activities depend on the integrity of brain function, nervous system development, and visual pathways $[86,87]$. 
Larvae were ready for experiment once swim bladder was formed

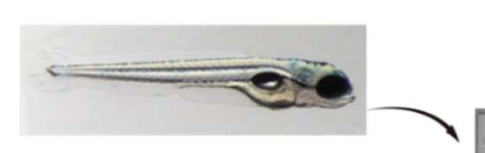

96 well plate, 1 larvae/well, $400 \mu \mathrm{L}$ of drug solution or sterile water per well, 12 larvae/group

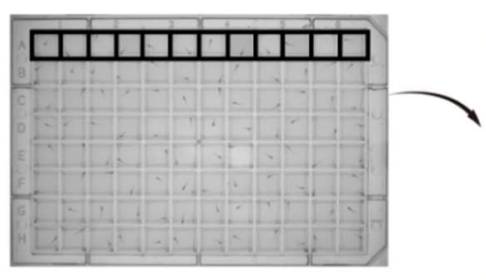

Average distance moved by the larvae was calculated in the timebins of 2 minute
Automatic tracking of larvae movement

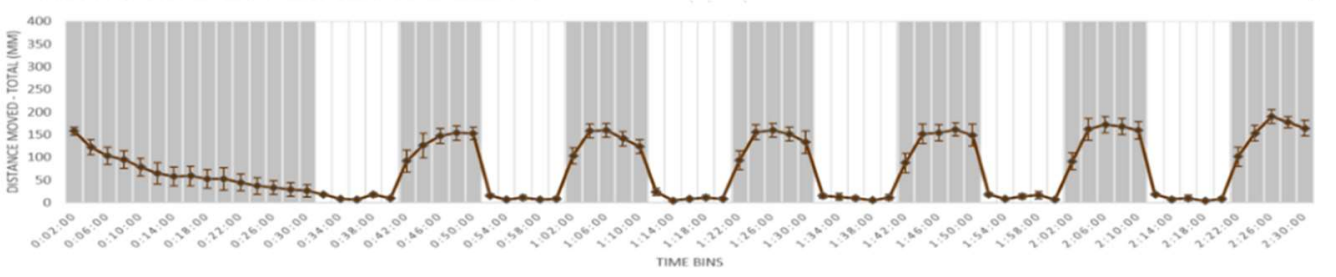

Figure 1. General scheme of the light-dark locomotion test. Zebrafish larvae were placed in a 96-well plate with one larva per well and $300 \mu \mathrm{L}$ of fish water. The plate containing the larvae was then placed in a Danio vision observation chamber following which the high-throughput tracking of zebrafish larvae was performed. The experiment duration was $2 \mathrm{~h}$ and $30 \mathrm{~min}$ and consisted of: $30 \mathrm{~min}$ of acclimatization, followed by 6 cycles of alternating light and dark periods. Each point in the graph represents the mean \pm SEM (standard error of mean) of the distance moved by zebrafish larvae in 2 min of time bins. The shaded part represents the dark period and the unshaded part represents the light period. The total number of embryos used was $12(n=12)$.

\section{Identification of Neuroactive Compounds}

\subsection{Light-Dark Locomotion Test}

The locomotor activity and pattern of zebrafish larvae in light and dark conditions have been used for high-throughput testing and screening of various substances for their neuroactive properties [83]. There are variations in the protocols used for performing the light-dark locomotion test $[83,88,89]$. The variations are in the stage of zebrafish larvae, number of wells in multi-well plates, and the length of experiments including the length of light and dark conditions, as shown in Table 1.

Table 1. Light-dark locomotion test protocols used by various studies for testing neuroactive compounds.

\begin{tabular}{|c|c|c|c|}
\hline Compounds & Stage and Well Plate & Protocol & References \\
\hline $\begin{array}{c}\text { Aconitine } \\
\text { Pentylenetrazol } \\
\text { 4-aminopyridine }\end{array}$ & $\begin{array}{l}4-6 \mathrm{dpf}, 48 \text { and } 96 \text { well } \\
\text { plates }\end{array}$ & $\begin{array}{l}4 \text { successive cycles of } 10 \text { min alternating } \\
\text { light and dark. }\end{array}$ & [90] \\
\hline $\begin{array}{c}\mathrm{Ag}+\text { and } \mathrm{AgNPs} \text { (silver } \\
\text { nanoparticles) }\end{array}$ & $5 \mathrm{dpf}, 48$ well plate & $\begin{array}{l}18 \text { alternating dark and light cycles of } \\
55 \text { min each. }\end{array}$ & [91] \\
\hline $\begin{array}{c}\text { Apomorphine } \\
\text { SKF-38393 } \\
\text { Quinpirole } \\
\text { Butaclamol } \\
\text { SCH-23390 } \\
\text { Haloperidol }\end{array}$ & $6 \mathrm{dpf}, 96$ well plate & $\begin{array}{l}10 \text { min acclimatization in dark followed by } \\
2 \text { cycles of } 10 \text { min of light and } 20 \text { min } \\
\text { of dark. }\end{array}$ & {$[92]$} \\
\hline $\begin{array}{l}\text { Bisphenol A (BPA) } \\
\text { Tetrabromobisphenol A (TBBPA) }\end{array}$ & $4-5 \mathrm{dpf}, 96$ well plate & $\begin{array}{l}20 \text { min of light followed by } 10 \text { min of dark } \\
\text { and } 10 \text { min of light. }\end{array}$ & {$[88]$} \\
\hline
\end{tabular}


Table 1. Cont.

\begin{tabular}{|c|c|c|c|}
\hline Compounds & Stage and Well Plate & Protocol & References \\
\hline $\begin{array}{c}\text { Chlorpyrifos } \\
\text { 6-hydroxy- } 2,2^{\prime}, 4,4^{\prime} \\
\text { tetrabromodiphenyl ether } \\
\text { (6-OH-BDE-47) }\end{array}$ & $6 \mathrm{dpf}, 96$ well plate & $\begin{array}{l}10 \text { min acclimatization followed by } 10 \mathrm{~min} \\
\text { alternating light and dark for } 2 \text { times. }\end{array}$ & [93] \\
\hline $\begin{array}{c}\text { Cocaine } \\
\text { Ethanol } \\
\text { D-Amphetamine }\end{array}$ & $6 \mathrm{dpf}, 96$ well plate & $\begin{array}{l}20 \text { min acclimatization in dark followed by } \\
10 \text { min of alternating light and dark for } \\
70 \mathrm{~min} \text {. }\end{array}$ & {$[83]$} \\
\hline Copper & $5 \mathrm{dpf}, 96$ well plate & $\begin{array}{l}4 \text { successive cycles of } 10 \text { min alternating } \\
\text { light and dark. }\end{array}$ & {$[94]$} \\
\hline $\begin{array}{l}\text { Copper ions, copper oxide } \\
\text { nanoparticles }\end{array}$ & $4 \mathrm{dpf}, 24$ well plate & $\begin{array}{l}18 \text { alternating cycles of } 5 \text { min of light and } \\
5 \text { min of dark. }\end{array}$ & [95] \\
\hline Diphenylhydantoin & $5 \mathrm{dpf}, 24$ well plate & $\begin{array}{l}10 \text { min acclimatization followed by } 30 \mathrm{~min} \\
\text { of light and } 5 \text { min of dark. }\end{array}$ & [52] \\
\hline Ethanol & $6 \mathrm{dpf}, 96$ well plate & $\begin{array}{l}20 \text { min acclimatization in dark followed by } \\
10 \text { min in dark and } 10 \text { min in light, then } \\
20 \text { min in dark, and then another cycle of } 10 \\
\text { min of light and } 20 \text { min of dark. }\end{array}$ & [84] \\
\hline Ethanol & $6 \mathrm{dpf}, 96$ well plate & $\begin{array}{c}15 \text { min in dark followed by } 15 \text { min in light } \\
\text { and } 15 \text { min in dark. }\end{array}$ & [96] \\
\hline Ethanol & $\begin{array}{l}9-10 \mathrm{dpf}, \\
24 \text { well plate }\end{array}$ & $\begin{array}{l}5 \text { min acclimatization in light followed by } \\
15 \text { min of dark and } 5 \text { min of light. }\end{array}$ & [97] \\
\hline Inorganic arsenic & $7 \mathrm{dpf}, 24$ well plate & $\begin{array}{c}\text { Acclimatization for } 10 \mathrm{~min} \text { followed by } \\
2 \text { successive cycles of } 10 \mathrm{~min} \text { of light and } \\
10 \mathrm{~min} \text { of dark. }\end{array}$ & [98] \\
\hline $\begin{array}{c}\text { MK-801; } \\
\text { Pentylenetetrazole; } \\
\text { Valproic acid sodium salt; } \\
\text { Yohimbine hydrochloride; } \\
\text { 5,5-Diphenylhydantoin sodium salt } \\
\text { Sulpiride }\end{array}$ & $7 \mathrm{dpf}, 24$ well plate & $\begin{array}{l}60 \mathrm{~min} \text { in light followed by } 5 \mathrm{~min} \text { in dark. } \\
\text { The activities of zebrafish larvae during the } \\
\text { last } 10 \mathrm{~min} \text { of } \\
\text { the light period and the } 5 \text { min of the dark } \\
\text { period were analyzed. }\end{array}$ & [99] \\
\hline Pentylenetetrazole & 5 and $7 \mathrm{dpf}, 24$ well plate & $\begin{array}{l}10 \text { min acclimatization in light followed by } \\
40 \text { min of light and then } 3 \text { successive cycles } \\
\text { of } 10 \text { min of light and } 5 \text { min of dark. }\end{array}$ & [100] \\
\hline $\begin{array}{l}\text { Pentylenetetrazole } \\
\text { Picrotoxin }\end{array}$ & $5 \mathrm{dpf}, 24$ well plate & $\begin{array}{l}25 \text { min of acclimatization } \\
\text { in environment followed by } 5 \text { min in light } \\
\text { and } 5 \text { min in dark. }\end{array}$ & [54] \\
\hline Perfluorooctane sulphate (PFOS) & $6 \mathrm{dpf}, 48$ well plate & $\begin{array}{l}15 \mathrm{~min} \text { acclimatization followed by } 10 \mathrm{~min} \\
\text { in dark and } 10 \mathrm{~min} \text { in light. }\end{array}$ & [101] \\
\hline $\begin{array}{l}\text { Polybrominated diphenyl ethers } \\
\text { and their hydroxyl metabolites } \\
\text { (OH-BDEs MeO-BDEs) }\end{array}$ & $\begin{array}{l}5,6 \text { and } 7 \mathrm{dpf}, \\
48 \text { well plate }\end{array}$ & $\begin{array}{l}10 \text { min light adaptation followed by two } \\
\text { repeated cycles of } 10 \text { min of dark and } \\
10 \text { min of light. }\end{array}$ & [89] \\
\hline $\begin{array}{l}2,2^{\prime}, 4,4^{\prime} \text {-Tetrabromodiphenyl } \\
\text { ether (BDE-47) }\end{array}$ & $5 \mathrm{dpf}, 24$ well plate & $\begin{array}{l}70 \text { min of alternating } 10 \text { min of light and } 10 \\
\text { min of dark starting with a light cycle. }\end{array}$ & [102] \\
\hline Tributyltin & $4 \mathrm{dpf}, 96$ well plate & $\begin{array}{l}50 \text { min of alternating } 10 \text { min of light and } 10 \\
\text { min of dark starting with a dark cycle. }\end{array}$ & [103] \\
\hline Venlafaxine & $5 \mathrm{dpf}, 96$ well plate & $\begin{array}{l}\text { Acclimatization for } 1 \mathrm{~h} \text { followed by } 60 \mathrm{~min} \\
\text { of alternating cycles of } 7.5 \mathrm{~min} \text { of light and } \\
7.5 \mathrm{~min} \text { of dark. }\end{array}$ & [104] \\
\hline Yohimbine & 5 and $7 \mathrm{dpf}, 24$ well plate & $\begin{array}{c}10 \text { min of acclimatization with light } \\
\text { followed by } 40 \text { min of light and three } \\
15 \text { min cycles of } 10 \text { min of light and } 5 \mathrm{~min} \\
\text { of dark. }\end{array}$ & [82] \\
\hline
\end{tabular}

We performed a light-dark locomotion test in which zebrafish larvae at $5 \mathrm{dpf}$ were exposed to two known neuroactive compounds-adrenaline and tricaine. Adrenaline is a non-selective agonist of adrenergic receptors acting as a main neurotransmitter in the autonomic nervous system [105]. Tricaine is a local anesthetic that is specifically used to induce anesthesia and euthanasia in fish. Tricaine induces nervous system suppression by blocking the sodium channels and thereby inhibiting 
the membrane excitability [106]. We found that adrenaline-treated larvae showed increased locomotor activity throughout the light and dark periods. Also, the response in the adrenaline-treated larvae was more robust than that of controls following the light-dark or dark-light transitions, as shown in Figure 2A. The effect of tricaine was opposite to that of adrenaline in that tricaine-treated larvae showed decreased locomotor activity in the dark condition, although the locomotor activity was similar to control in the light condition, as shown in Figure 2B. Also, the responses to dark-light and light-dark transition were attenuated in the tricaine-treated larvae. Adrenaline is a neuro-stimulant and its exposure increased the locomotor activity and aggravated the startle response in zebrafish larvae, whereas tricaine-a CNS depressant-decreased the locomotor activity and attenuated the startle response in zebrafish larvae. These stimulatory and depressant responses elicited by neuroactive drugs in zebrafish larvae can be exploited in high-throughput screening to identify neuroactive compounds. Thus, zebrafish larvae are sensitive to light and dark conditions and transition from light to dark conditions and vice versa. Treatment of zebrafish larvae with neuroactive substances could change the response pattern of the larvae, which could then be used to determine whether a substance has a neuroactive property or not.

\subsection{Neuroactive Drugs}

Using d-amphetamine, cocaine, and ethanol, Irons et al. showed that zebrafish larvae are sensitive to neuroactive drugs and their locomotor response is like that of mammals [83]. Cocaine and low-dose amphetamine increased locomotor activity in zebrafish larvae, which is similar to their effects in humans where they act as a CNS stimulant and increase motor activity. Zebrafish larvae treated with low-dose ethanol $(1 \%)$ showed an increased locomotor activity $[83,84,96,97]$ whereas those treated with higher dose ethanol showed a decreased locomotor activity as compared with the controls. This effect of ethanol in zebrafish larvae is similar to that in humans, where low-dose ethanol acts as a CNS stimulant, whereas high-dose ethanol act as a CNS depressant [107].

Convulsant drugs, such as pentylenetetrazole and picrotoxin, had similar effects. They caused dose-dependent increases in locomotor activity in zebrafish larvae. At lower concentrations, they caused increased locomotor activity in the dark condition, whereas at the higher concentrations they induced a reversal of normal patterns of activity in zebrafish larvae, i.e., a dark-light transition eliciting an increased activity and a light-dark transition eliciting a decreased activity $[54,90,100]$. The similar responses of PTZ and picrotoxin in zebrafish larvae could be due to their similar mechanisms of action as both of them are GABA receptor antagonists. Similarly, convulsant drugs such as 4-aminopyridine, a potassium channel blocker and aconitine, a voltage gated sodium channel agonist, also induced increased locomotor activity in zebrafish larvae in the dark condition [90]. Thus, the convulsant drugs showed similar effects in zebrafish larvae. In particular, they increased locomotor activity, specifically in the dark condition of the light-dark locomotion test. Besides, most of these drugs also induced a robust startle response following the light to dark transition and the larvae took longer time to return to the baseline movement following the dark to light transition $[54,90,100]$.

The effect of anticonvulsant drugs in the zebrafish larvae was expectedly opposite to that of convulsant drugs. Antiepileptic drugs such as diphenylhydantoin (DPH) and sodium valproic acid showed a decrease in locomotor activity in zebrafish larvae in both the dark and light conditions [52]. DPH is a sodium channel blocker and acts by modifying the glutamatergic transmission [108]. Studies done in rodents have shown that DPH blocks the increase of locomotor activity induced by methylphenidate treatment or electroconvulsive shock $[109,110]$. Sodium valproate acts by increasing the level of GABA, inhibiting voltage-gated sodium channels [8], and modulating the NMDA receptor-mediated actions [111]. MK 801 (dizocilpine)—an NMDA receptor antagonist-decreased the movement in zebrafish larvae in both the light and dark conditions. The NMDA receptor is required for the glutamate-induced excitatory neurotransmission. The decrease in movement in larvae treated with MK 801 could be due to the inhibition of excitatory neurotransmitter glutamate [99]. MK 801 also acts as a potent anticonvulsant and similar to DPH and sodium valproate, it decreased the locomotor 
activity in zebrafish larvae [99]. Therefore, the neurodepressant effect of anticonvulsant drugs is confirmed by the marked decrease in locomotor activity in zebrafish larvae.
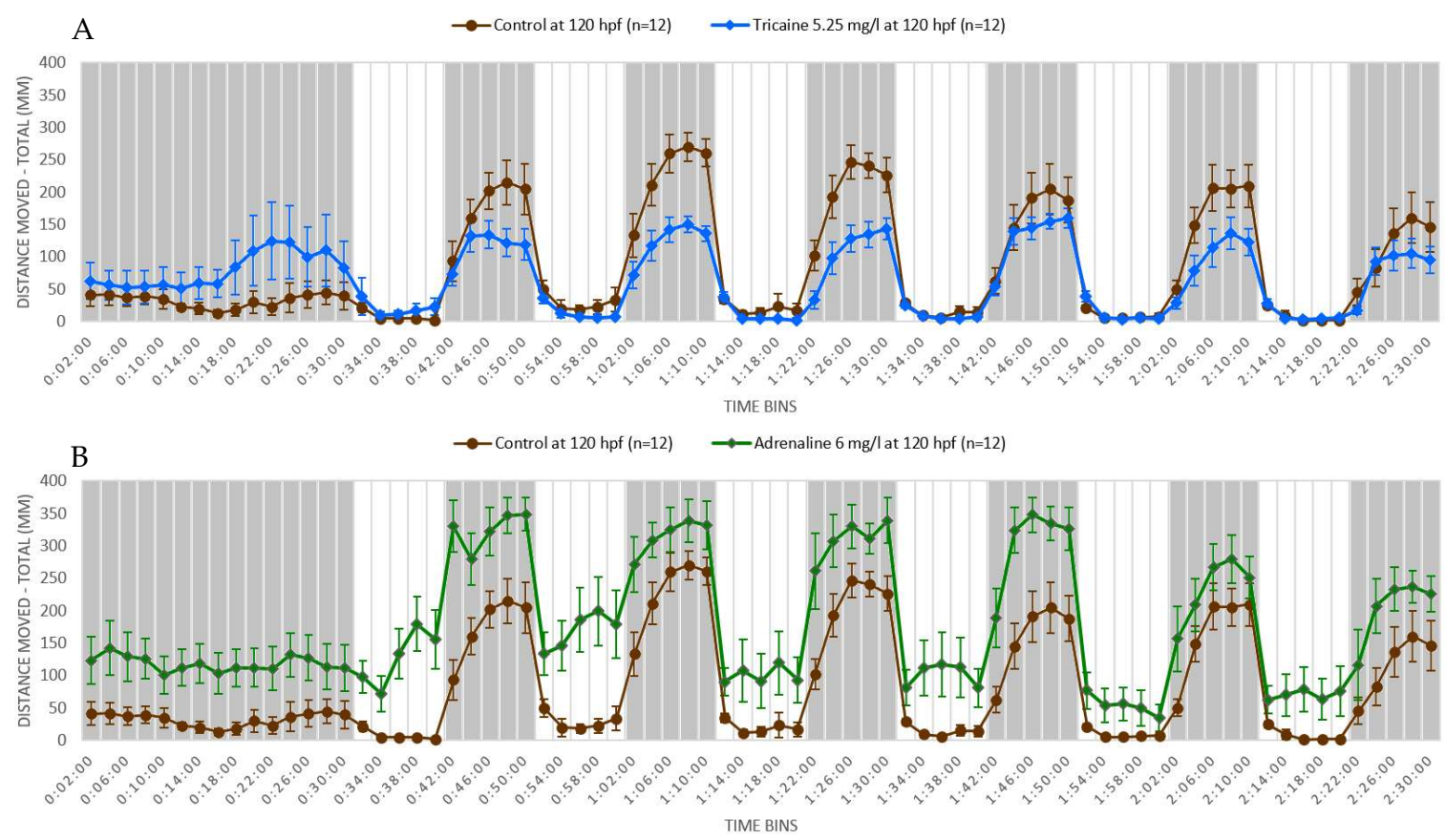

Figure 2. Swimming pattern of $A B$ wild type zebrafish larvae after drug treatment. Zebrafish larvae ( $n=12$ for each drug) at $5 \mathrm{dpf}$ were exposed to sterile water (used as control), adrenaline $0.03 \mathrm{mM}$ $(6 \mathrm{mg} / \mathrm{L})$, and tricaine $0.02 \mathrm{mM}(5.25 \mathrm{mg} / \mathrm{L})$. The total volume of drug solution or sterile water used was $300 \mu \mathrm{L}$ per well. The exposure was started half an hour before the experiment and continued till the conclusion of the experiment. The experiment protocol was the same as described in Figure 1. The results were calculated as mean \pm SEM of the distance moved by each experimental group in 2 min of time bins. Adrenaline-treated zebrafish larvae showed increased movement throughout the experiment (A). On the contrary, tricaine-treated zebrafish larvae showed decreased movement throughout the experiment (B). $n=12$ for each experimental group.

Yohimbine - an alpha 2 adrenergic receptor antagonist-increased the locomotor activity in the dark condition [99], but at higher concentrations, it reduced the locomotor activity in both the light and dark conditions $[82,99]$. This effect of yohimbine in zebrafish is similar to that observed in rodents. The decrease in locomotor activity observed at higher concentrations could be due to the alpha1 adrenergic receptor antagonism [82]. Similarly, venlafaxine-a serotonin-norepinephrine reuptake inhibitor-also induced a decrease in locomotor activity in the dark condition in zebrafish larvae [104]. However, this effect of venlafaxine in zebrafish larvae is opposite to that observed in rodents, where it was shown to increase the locomotor activity $[112,113]$.

Drugs affecting dopaminergic receptors showed an altered locomotor activity in a dose-dependent manner in the light-dark locomotion test in zebrafish larvae. Selective dopamine agonists like SKF-38393 and quinpirole increased the locomotor activity and selective dopamine antagonists like SCH-23390 and haloperidol decreased the locomotor activity in zebrafish larvae. Non-selective dopamine agonists and antagonists showed biphasic effects. Apomorphine-a non-selective dopamine agonist-induced an increase in locomotor activity at lower doses and decreased it at the higher doses. In contrast, butaclamol—a non-selective dopamine antagonist—induced a decrease in locomotor activity at higher doses and increased it at the lower doses [92]. The locomotor behavior induced by these drugs are similar in both mammals and zebrafish larvae [92].

Most of the neuroactive drugs that have been studied showed altered locomotor activity in the light-dark locomotion test in zebrafish larvae. In addition, the effects produced by these neuroactive 
drugs in zebrafish larvae usually confirm the one detected in other higher animals. However, not all neuroactive drugs induced alteration in the locomotor activity or pattern of zebrafish larvae. For instance, sulpiride-a dopamine receptor antagonist—did not alter the movement in zebrafish larvae [99].

\subsection{Metals, Metallic Ions, and Nanoparticles}

The light-dark locomotion test in zebrafish larvae is also used to study the developmental neurotoxicity of metals, metallic ions, and metallic nanoparticles, such as methylmercury, copper, and silver $[91,94,95,114]$. Methylmercury is a known neurotoxicant and it decreases locomotion in zebrafish larvae [114]. Although the mechanism of action is unknown, this effect is similar to that observed in rodents, where it also decreases the locomotor activity [115] and exploratory activity [116]. Metals such as copper and silver are increasingly used in nanoparticles. The light-dark locomotion test has been utilized to study the neurobehavioral effects of these metals and their nanoparticles in zebrafish larvae. In the light-dark locomotion test, both copper and silver altered the locomotor activity in zebrafish larvae at sublethal concentrations. Copper decreased the locomotor activity in the dark condition and increased it in the light condition. Copper nanoparticles, however, showed an increase in locomotor activity only in the light condition [94,95]. Silver showed a biphasic effect, i.e., it increased the locomotor activity at lower concentrations and decreased it at higher concentrations. Silver nanoparticles decreased the locomotor activity irrespective of the concentrations [91]. Thus, the light-dark locomotion test in zebrafish larvae could be utilized in screening the neuroactivity of metals, their ions, and nanoparticles.

\subsection{Environmental Toxicants}

Zebrafish larvae are also increasingly used for studying the behavioral toxicity of environmental toxicants $[88-90,98,102]$. The study of toxicants-induced behavior alteration in zebrafish larvae is important as it not only provides their effect in aquatic life, but also gives a clue about the neurobehavioral effects they cause in the broader ecosystem, including humans. The behavior of zebrafish larvae is modulated by the environmental toxicants. The light-dark locomotion test has been applied for studying the effects of several environmental toxicants such as tetrabromodiphenylether (6-OH-BDE-47), chlorpyrifos, perfluorooctane sulphate (PFOS), and dechlorane plus (DP) [89,93,101,102]. Chlorpyrifos and (6-OH-BDE-47) are known neurotoxicants [93] whereas PFOS accumulates in the brain and has potential neurotoxic effects [101]. These neurotoxicants showed altered locomotor activity in zebrafish larvae. Chlorpyrifos and 6-OH-BDE-47 decreased the locomotor activity $[89,93,102]$ and PFOS showed a biphasic pattern with an abrupt increase in locomotor activity followed by a transient decrease before reaching the plateau effect following transition from light to dark [101]. DP decreased the locomotor activity in zebrafish larvae by inhibiting the axonal growth of primary motor neurons [102]. Some environmental toxicants showed neurobehavioral alterations similar to those observed in rodent models. For instance, arsenic showed increased locomotor activity [98] and tributyltin significantly reduced the locomotor activity [103] in zebrafish larvae. These effects were similar to that described in the rodent models where arsenic is shown to cause an increase in locomotor activity [98] and tributyltin is shown to cause a dose-dependent decrease in spontaneous motor activity [117]. Thus, the light-dark locomotion test in zebrafish larvae has been successfully employed for the study of neurobehavioral alterations caused by various environmental toxicants.

\section{Conclusions}

Zebrafish larvae provide the advantage of performing large-scale high-throughput screening of thousands of neuroactive compounds in a day. The small size, rapid development, easy manipulation, cost-effectiveness, and availability of large numbers of eggs are some of the major advantages of the larvae model compared to the adult zebrafish and other vertebrate models. Zebrafish larvae are gaining popularity for behavioral studies due to their robust behavioral repertoire, similarity to higher 
vertebrates, and the possibility of conducting high-throughput research. The analysis of locomotor behavior by the light-dark locomotion test is increasingly utilized for the screening of neuroactive compounds. Numerous experiments conducted across different labs using various protocols over the years have shown that the light-dark locomotion test can be successfully used for the screening and analysis of neuroactive compounds. In addition, it could be a complementary test in evaluating and determining the neuroactivity of putative neuroactive compounds.

Author Contributions: Conceptualization, R.M.B., D.Z., and M.M.; writing—original draft preparation, R.M.B. and D.Z.; experiments and data analysis, R.M.B. and S.T.; writing - review and editing, D.F. and M.M.

Funding: This research was funded by DIFF (Drug documentation, information and education) Research Centre, University of Brescia.

Conflicts of Interest: The authors declare no conflict of interest.

\section{References}

1. Kalueff, A.V.; Echevarria, D.J.; Stewart, A.M. Gaining translational momentum: More zebrafish models for neuroscience research. Prog. Neuro-Psychopharmacol. Biol. Psychiatry 2014, 55, 1-6. [CrossRef]

2. Basnet, R.M.; Zizioli, D.; Guarienti, M.; Finazzi, D.; Memo, M. Methylxanthines induce structural and functional alterations of the cardiac system in zebrafish embryos. BMC Pharmacol. Toxicol. 2017, 18, 72. [CrossRef] [PubMed]

3. Lawrence, C. The husbandry of zebrafish (danio rerio): A review. Aquaculture 2007, 269, 1-20. [CrossRef]

4. Howe, K.; Clark, M.D.; Torroja, C.F.; Torrance, J.; Berthelot, C.; Muffato, M.; Collins, J.E.; Humphray, S.; McLaren, K.; Matthews, L.; et al. The zebrafish reference genome sequence and its relationship to the human genome. Nature 2013, 496, 498-503. [CrossRef]

5. Kalueff, A.V.; Stewart, A.M.; Gerlai, R. Zebrafish as an emerging model for studying complex brain disorders. Trends Pharmacol. Sci. 2014, 35, 63-75. [CrossRef] [PubMed]

6. Friedrich, T.; Lambert, A.M.; Masino, M.A.; Downes, G.B. Mutation of zebrafish dihydrolipoamide branched-chain transacylase 2 results in motor dysfunction and models maple syrup urine disease. Dis. Models Mech. 2012, 5, 248-258. [CrossRef]

7. Lange, M.; Norton, W.; Coolen, M.; Chaminade, M.; Merker, S.; Proft, F.; Schmitt, A.; Vernier, P.; Lesch, K.P.; Bally-Cuif, L. The adhd-susceptibility gene lphn3.1 modulates dopaminergic neuron formation and locomotor activity during zebrafish development. Mol. Psychiatry 2012, 17, 946-954. [CrossRef] [PubMed]

8. Levitas-Djerbi, T.; Appelbaum, L. Modeling sleep and neuropsychiatric disorders in zebrafish. Curr. Opin. Neurobiol. 2017, 44, 89-93. [CrossRef] [PubMed]

9. Morris, J.A. Zebrafish: A model system to examine the neurodevelopmental basis of schizophrenia. Prog. Brain Res. 2009, 179, 97-106.

10. Norton, W.H. Toward developmental models of psychiatric disorders in zebrafish. Front. Neural Circuits 2013, 7, 79. [CrossRef] [PubMed]

11. Stewart, A.M.; Braubach, O.; Spitsbergen, J.; Gerlai, R.; Kalueff, A.V. Zebrafish models for translational neuroscience research: From tank to bedside. Trends Neurosci. 2014, 37, 264-278. [CrossRef]

12. Lau, B.Y.; Mathur, P.; Gould, G.G.; Guo, S. Identification of a brain center whose activity discriminates a choice behavior in zebrafish. Proc. Natl. Acad. Sci. USA 2011, 108, 2581-2586. [CrossRef] [PubMed]

13. Lucini, C.; D'Angelo, L.; Cacialli, P.; Palladino, A.; de Girolamo, P. BDNF, brain, and regeneration: Insights from zebrafish. Int. J. Mol. Sci. 2018, 19, 3155. [CrossRef]

14. Perathoner, S.; Cordero-Maldonado, M.L.; Crawford, A.D. Potential of zebrafish as a model for exploring the role of the amygdala in emotional memory and motivational behavior. J. Neurosci. Res. 2016, 94, 445-462. [CrossRef] [PubMed]

15. Randlett, O.; Wee, C.L.; Naumann, E.A.; Nnaemeka, O.; Schoppik, D.; Fitzgerald, J.E.; Portugues, R.; Lacoste, A.M.; Riegler, C.; Engert, F.; et al. Whole-brain activity mapping onto a zebrafish brain atlas. Nat. Methods 2015, 12, 1039-1046. [CrossRef] [PubMed]

16. Kalueff, A.V.; Gebhardt, M.; Stewart, A.M.; Cachat, J.M.; Brimmer, M.; Chawla, J.S.; Craddock, C.; Kyzar, E.J.; Roth, A.; Landsman, S.; et al. Towards a comprehensive catalog of zebrafish behavior 1.0 and beyond. Zebrafish 2013, 10, 70-86. [CrossRef] [PubMed] 
17. Tegelenbosch, R.A.J.; Noldus, L.P.J.J.; Richardson, M.K.; Ahmad, F. Zebrafish embryos and larvae in behavioural assays. Behaviour 2012, 149, 1241-1281. [CrossRef]

18. Friedrich, R.W.; Jacobson, G.A.; Zhu, P. Circuit neuroscience in zebrafish. Curr. Biol. 2010, 20, R371-R381. [CrossRef] [PubMed]

19. Kokel, D.; Bryan, J.; Laggner, C.; White, R.; Cheung, C.Y.; Mateus, R.; Healey, D.; Kim, S.; Werdich, A.A.; Haggarty, S.J.; et al. Rapid behavior-based identification of neuroactive small molecules in the zebrafish. Nat. Chem. Biol. 2010, 6, 231-237. [CrossRef]

20. Kokel, D.; Peterson, R.T. Chemobehavioural phenomics and behaviour-based psychiatric drug discovery in the zebrafish. Brief. Funct. Genom. Proteom. 2008, 7, 483-490. [CrossRef]

21. Fleming, A.; National Centre for the Replacement, Refinement, and Reduction of Animals in Research (Great Britain). Zebrafish as an Alternative Model Organism for Disease Modelling and Drug Discovery: Implications for the 3Rs; National Centre for the Replacement, Refinement and Reduction of Animals in Research: London, UK, 2007.

22. Lorenzetti, S.; Altieri, I.; Arabi, S.; Balduzzi, D.; Bechi, N.; Cordelli, E.; Galli, C.; Ietta, F.; Modina, S.C.; Narciso, L.; et al. Innovative non-animal testing strategies for reproductive toxicology: The contribution of italian partners within the eu project reprotect. Annali dell'Istituto Superiore di Sanita 2011, 47, 429-444.

23. Palmer, T.; Ek, F.; Enqvist, O.; Olsson, R.; Astrom, K.; Petersson, P. Action sequencing in the spontaneous swimming behavior of zebrafish larvae - implications for drug development. Sci. Rep. 2017, 7, 3191. [CrossRef] [PubMed]

24. Orger, M.B.; de Polavieja, G.G. Zebrafish behavior: Opportunities and challenges. Annu. Rev. Neurosci. 2017, 40, 125-147. [CrossRef] [PubMed]

25. Saint-Amant, L.; Drapeau, P. Time course of the development of motor behaviors in the zebrafish embryo. J. Neurobiol. 1998, 37, 622-632. [CrossRef]

26. Buss, R.R.; Pierre, D. Synaptic drive to motoneurons during fictive swimming in the developing zebrafish. J. Neurophysiol. 2001, 86, 197-210. [CrossRef]

27. Drapeau, P.; Saint-Amant1, L.; Buss, R.R.; Chong, M.; McDearmid, J.R.; Brustein, E. Development of the locomotor network in zebrafish. Prog. Neurobiol. 2002, 68, 85-111. [CrossRef]

28. Brustein, E.; Saint-Amant, L.; Buss, R.R.; Chong, M.; McDearmid, J.R.; Drapeau, P. Steps during the development of the zebrafish locomotor network. J. Physiol. (Paris) 2003, 97, 77-86. [CrossRef] [PubMed]

29. Burgess, H.A.; Granato, M. Modulation of locomotor activity in larval zebrafish during light adaptation. J. Exp. Biol. 2007, 210, 2526-2539. [CrossRef]

30. Lowery, L.A.; Sive, H. Strategies of vertebrate neurulation and a re-evaluation of teleost neural tube formation. Mech. Dev. 2004, 121, 1189-1197. [CrossRef] [PubMed]

31. Tropepe, V.; Sive, H.L. Can zebrafish be used as a model to study the neurodevelopmental causes of autism? Genes Brain Behav. 2003, 2, 268-281. [CrossRef] [PubMed]

32. Panula, P.; Chen, Y.C.; Priyadarshini, M.; Kudo, H.; Semenova, S.; Sundvik, M.; Sallinen, V. The comparative neuroanatomy and neurochemistry of zebrafish cns systems of relevance to human neuropsychiatric diseases. Neurobiol. Dis. 2010, 40, 46-57. [CrossRef] [PubMed]

33. Filippi, A.; Mahler, J.; Schweitzer, J.; Driever, W. Expression of the paralogous tyrosine hydroxylase encoding genes th1 and th2 reveals the full complement of dopaminergic and noradrenergic neurons in zebrafish larval and juvenile brain. J. Comp. Neurol. 2010, 518, 423-438. [CrossRef] [PubMed]

34. Kozol, R.A.; Abrams, A.J.; James, D.M.; Buglo, E.; Yan, Q.; Dallman, J.E. Function over form: Modeling groups of inherited neurological conditions in zebrafish. Front. Mol. Neurosci. 2016, 9, 55. [CrossRef]

35. Jarvis, E.D.; Gunturkun, O.; Bruce, L.; Csillag, A.; Karten, H.; Kuenzel, W.; Medina, L.; Paxinos, G.; Perkel, D.J.; Shimizu, T.; et al. Avian brains and a new understanding of vertebrate brain evolution. Nat. Rev. Neurosci. 2005, 6, 151-159. [CrossRef]

36. Fosque, B.F.; Sun, Y.; Dana, H.; Yang, C.T.; Ohyama, T.; Tadross, M.R.; Patel, R.; Zlatic, M.; Kim, D.S.; Ahrens, M.B.; et al. Neural circuits. Labeling of active neural circuits in vivo with designed calcium integrators. Science (New York) 2015, 347, 755-760. [CrossRef]

37. Panier, T.; Romano, S.A.; Olive, R.; Pietri, T.; Sumbre, G.; Candelier, R.; Debregeas, G. Fast functional imaging of multiple brain regions in intact zebrafish larvae using selective plane illumination microscopy. Front. Neural Circuits 2013, 7, 65. [CrossRef] 
38. Kimmel, C.B.; Ballard, W.W.; Kimmel, S.R.; Ullmann, B.; Schilling, T.F. Stages of embryonic development of the zebrafish. Dev. Dyn. Off. Publ. Am. Assoc. Anat. 1995, 203, 253-310. [CrossRef] [PubMed]

39. Adams, M.M.; Kafaligonul, H. Zebrafish-a model organism for studying the neurobiological mechanisms underlying cognitive brain aging and use of potential interventions. Front. Cell Dev. Biol. 2018, 6, 135. [CrossRef] [PubMed]

40. Heffern, K.; Tierney, K.; Gallagher, E.P. Comparative effects of cadmium, zinc, arsenic and chromium on olfactory-mediated neurobehavior and gene expression in larval zebrafish (danio rerio). Aquat. Toxicol. (Amsterdam) 2018, 201, 83-90. [CrossRef]

41. Liu, C.X.; Li, C.Y.; Hu, C.C.; Wang, Y.; Lin, J.; Jiang, Y.H.; Li, Q.; Xu, X. Crispr/cas9-induced shank3b mutant zebrafish display autism-like behaviors. Mol. Autism 2018, 9, 23. [CrossRef]

42. Norton, W.; Bally-Cuif, L. Adult zebrafish as a model organism for behavioural genetics. BMC Neurosci. 2010, 11, 90. [CrossRef]

43. Spence, R.; Gerlach, G.; Lawrence, C.; Smith, C. The behaviour and ecology of the zebrafish, danio rerio. Biol. Rev. Camb. Philos. Soc. 2008, 83, 13-34. [CrossRef]

44. Khatri, D.; Zizioli, D.; Trivedi, A.; Borsani, G.; Monti, E.; Finazzi, D. Overexpression of human mutant pank2 proteins affects development and motor behavior of zebrafish embryos. Neuromol. Med. 2018. [CrossRef]

45. Muniandy, Y. The use of larval zebrafish (danio rerio) model for identifying new anxiolytic drugs from herbal medicine. Zebrafish 2018, 15, 321-339. [CrossRef]

46. Bruni, G.; Lakhani, P.; Kokel, D. Discovering novel neuroactive drugs through high-throughput behavior-based chemical screening in the zebrafish. Front. Pharmacol. 2014, 5, 153. [CrossRef]

47. Fontana, B.D.; Mezzomo, N.J.; Kalueff, A.V.; Rosemberg, D.B. The developing utility of zebrafish models of neurological and neuropsychiatric disorders: A critical review. Exp. Neurol. 2018, 299, 157-171. [CrossRef] [PubMed]

48. Khan, K.M.; Collier, A.D.; Meshalkina, D.A.; Kysil, E.V.; Khatsko, S.L.; Kolesnikova, T.; Morzherin, Y.Y.; Warnick, J.E.; Kalueff, A.V.; Echevarria, D.J. Zebrafish models in neuropsychopharmacology and cns drug discovery. Br. J. Pharmacol. 2017, 174, 1925-1944. [CrossRef] [PubMed]

49. Lamprea, M.R.; Cardenas, F.P.; Setem, J.; Morato, S. Thigmotactic responses in an open-field. Braz. J. Med. Biol. Res. = Revista Brasileira de Pesquisas Medicas e Biologicas 2008, 41, 135-140. [CrossRef] [PubMed]

50. Simon, P.; Dupuis, R.; Costentin, J. Thigmotaxis as an index of anxiety in mice. Influence of dopaminergic transmissions. Behav. Brain Res. 1994, 61, 59-64. [CrossRef]

51. Colwill, R.M.; Creton, R. Imaging escape and avoidance behavior in zebrafish larvae. Rev. Neurosci. 2011, 22, 63-73. [CrossRef] [PubMed]

52. Liu, X.; Lin, J.; Zhang, Y.; Peng, X.; Guo, N.; Li, Q. Effects of diphenylhydantoin on locomotion and thigmotaxis of larval zebrafish. Neurotoxicol. Teratol. 2016, 53, 41-47. [CrossRef] [PubMed]

53. Schnorr, S.J.; Steenbergen, P.J.; Richardson, M.K.; Champagne, D.L. Measuring thigmotaxis in larval zebrafish. Behav. Brain Res. 2012, 228, 367-374. [CrossRef] [PubMed]

54. Yang, X.; Lin, J.; Peng, X.; Zhang, Q.; Zhang, Y.; Guo, N.; Zhou, S.; Li, Q. Effects of picrotoxin on zebrafish larvae behaviors: A comparison study with ptz. Epilepsy Behav. 2017, 70, 224-231. [CrossRef]

55. Lundegaard, P.R.; Anastasaki, C.; Grant, N.J.; Sillito, R.R.; Zich, J.; Zeng, Z.; Paranthaman, K.; Larsen, A.P.; Armstrong, J.D.; Porteous, D.J.; et al. Mek inhibitors reverse camp-mediated anxiety in zebrafish. Chem. Biol. 2015, 22, 1335-1346. [CrossRef] [PubMed]

56. Fetcho, J.R.; McLean, D.L. Startle response. In Encyclopedia of Neuroscience; Squire, L.R., Ed.; Elsevier Ltd.: Amsterdam, The Netherlands, 2009; pp. 375-379.

57. Ganzen, L.; Venkatraman, P.; Pang, C.P.; Leung, Y.F.; Zhang, M. Utilizing zebrafish visual behaviors in drug screening for retinal degeneration. Int. J. Mol. Sci. 2017, 18, 1185. [CrossRef] [PubMed]

58. Best, J.D.; Berghmans, S.; Hunt, J.J.; Clarke, S.C.; Fleming, A.; Goldsmith, P.; Roach, A.G. Non-associative learning in larval zebrafish. Neuropsychopharmacol. Off. Publ. Am. Coll. Neuropsychopharmacol. 2008, 33, 1206-1215. [CrossRef]

59. Zeddies, D.G.; Fay, R.R. Development of the acoustically evoked behavioral response in zebrafish to pure tones. J. Exp. Biol. 2005, 208, 1363-1372. [CrossRef]

60. Mena, A.; Ruiz-Salas, J.C.; Puentes, A.; Dorado, I.; Ruiz-Veguilla, M.; De la Casa, L.G. Reduced prepulse inhibition as a biomarker of schizophrenia. Front. Behav. Neurosci. 2016, 10, 202. [CrossRef] 
61. Huang, Y.Y.; Neuhauss, S.C. The optokinetic response in zebrafish and its applications. Front. Biosci. J. Virtual Library 2008, 13, 1899-1916. [CrossRef]

62. Easter, S.S., Jr.; Nicola, G.N. The development of eye movements in the zebrafish (danio rerio). Dev. Psychobiol. 1997, 31, 267-276. [CrossRef]

63. Brockerhoff, S.E. Measuring the optokinetic response of zebrafish larvae. Nat. Protoc. 2006, 1, $2448-2451$. [CrossRef] [PubMed]

64. Cahill, H.; Nathans, J. The optokinetic reflex as a tool for quantitative analyses of nervous system function in mice: Application to genetic and drug-induced variation. PLoS ONE 2008, 3, e2055. [CrossRef] [PubMed]

65. Fleisch, V.C.; Neuhauss, S.C. Visual behavior in zebrafish. Zebrafish 2006, 3, 191-201. [CrossRef]

66. Orger, M.B.; Baier, H. Channeling of red and green cone inputs to the zebrafish optomotor response. Vis. Neurosci. 2005, 22, 275-281. [CrossRef] [PubMed]

67. Roeser, T.; Baier, H. Visuomotor behaviors in larval zebrafish after gfp-guided laser ablation of the optic tectum. J. Neurosci. Off. J. Soc. Neurosci. 2003, 23, 3726-3734. [CrossRef]

68. Thompson, R.F.; Spencer, W.A. Habituation: A model phenomenon for the study of neuronal substrates of behavior. Psychol. Rev. 1966, 73, 16-43. [CrossRef] [PubMed]

69. Wolman, M.A.; Jain, R.A.; Marsden, K.C.; Bell, H.; Skinner, J.; Hayer, K.E.; Hogenesch, J.B.; Granato, M. A genome-wide screen identifies papp-aa-mediated igfr signaling as a novel regulator of habituation learning. Neuron 2015, 85, 1200-1211. [CrossRef]

70. Muto, A.; Kawakami, K. Prey capture in zebrafish larvae serves as a model to study cognitive functions. Front. Neural Circuits 2013, 7, 110. [CrossRef]

71. Borla, M.A.; Palecek, B.; Budick, S.; O’Malley, D.M. Prey capture by larval zebrafish: Evidence for fine axial motor control. Brain Behav. Evol. 2002, 60, 207-229. [CrossRef]

72. Gahtan, E.; Tanger, P.; Baier, H. Visual prey capture in larval zebrafish is controlled by identified reticulospinal neurons downstream of the tectum. J. Neurosci. Off. J. Soc. Neurosci. 2005, 25, 9294-9303. [CrossRef] [PubMed]

73. Sorribes, A.; Thornorsteinsson, H.; Arnardottir, H.; Johannesdottir, I.; Sigurgeirsson, B.; de Polavieja, G.G.; Karlsson, K.A.E. The ontogeny of sleep-wake cycles in zebrafish: A comparison to humans. Front. Neural Circuits 2013, 7, 178. [CrossRef]

74. Zhdanova, I.V. Sleep in zebrafish. Zebrafish 2006, 3, 215-226. [CrossRef]

75. Rihel, J.; Prober, D.A.; Arvanites, A.; Lam, K.; Zimmerman, S.; Jang, S.; Haggarty, S.J.; Kokel, D.; Rubin, L.L.; Peterson, R.T.; et al. Zebrafish behavioral profiling links drugs to biological targets and rest/wake regulation. Science (New York) 2010, 327, 348-351. [CrossRef]

76. Rihel, J.; Schier, A.F. Behavioral screening for neuroactive drugs in zebrafish. Dev. Neurobiol. 2012, 72, 373-385. [CrossRef]

77. Sigurgeirsson, B.; Thorsteinsson, H.; Arnardottir, H.; Johannesdottir, I.T.; Karlsson, K.A. Effects of modafinil on sleep-wake cycles in larval zebrafish. Zebrafish 2011, 8, 133-140. [CrossRef]

78. Wang, Y.-N.; Hou, Y.-Y.; Sun, M.-Z.; Zhang, C.-Y.; Bai, G.; Zhao, X.; Feng, X.-Z. Behavioural screening of zebrafish using neuroactive traditional chinese medicine prescriptions and biological targets. Sci. Rep. 2014, 4, 5311. [CrossRef] [PubMed]

79. Hernandez, R.E.; Galitan, L.; Cameron, J.; Goodwin, N.; Ramakrishnan, L. Delay of initial feeding of zebrafish larvae until 8 days postfertilization has no impact on survival or growth through the juvenile stage. Zebrafish 2018, 15, 515-518. [CrossRef]

80. Grillner, S.; Markram, H.; De Schutter, E.; Silberberg, G.; LeBeau, F.E. Microcircuits in action-From cpgs to neocortex. Trends Neurosci. 2005, 28, 525-533. [CrossRef] [PubMed]

81. Horzmann, K.A.; Freeman, J.L. Zebrafish get connected: Investigating neurotransmission targets and alterations in chemical toxicity. Toxics 2016, 4, 19. [CrossRef] [PubMed]

82. Li, Q.; Lin, J.; Zhang, Y.; Liu, X.; Chen, X.Q.; Xu, M.Q.; He, L.; Li, S.; Guo, N. Differential behavioral responses of zebrafish larvae to yohimbine treatment. Psychopharmacology 2015, 232, 197-208. [CrossRef] [PubMed]

83. Irons, T.D.; MacPhail, R.C.; Hunter, D.L.; Padilla, S. Acute neuroactive drug exposures alter locomotor activity in larval zebrafish. Neurotoxicol. Teratol. 2010, 32, 84-90. [CrossRef] [PubMed]

84. MacPhail, R.C.; Brooks, J.; Hunter, D.L.; Padnos, B.; Irons, T.D.; Padilla, S. Locomotion in larval zebrafish: Influence of time of day, lighting and ethanol. Neurotoxicology 2009, 30, 52-58. [CrossRef] [PubMed] 
85. Vignet, C.; Begout, M.L.; Pean, S.; Lyphout, L.; Leguay, D.; Cousin, X. Systematic screening of behavioral responses in two zebrafish strains. Zebrafish 2013, 10, 365-375. [CrossRef]

86. Ali, S.; Champagne, D.L.; Richardson, M.K. Behavioral profiling of zebrafish embryos exposed to a panel of 60 water-soluble compounds. Behav. Brain Res. 2012, 228, 272-283. [CrossRef]

87. Bilotta, J. Effects of abnormal lighting on the development of zebrafish visual behavior. Behav. Brain Res. 2000, 116, 81-87. [CrossRef]

88. Fraser, T.W.K.; Khezri, A.; Jusdado, J.G.H.; Lewandowska-Sabat, A.M.; Henry, T.; Ropstad, E. Toxicant induced behavioural aberrations in larval zebrafish are dependent on minor methodological alterations. Toxicol. Lett. 2017, 276, 62-68. [CrossRef]

89. Zhang, B.; Xu, T.; Huang, G.; Yin, D.; Zhang, Q.; Yang, X. Neurobehavioral effects of two metabolites of bde-47 (6-oh-bde-47 and 6-meo-bde-47) on zebrafish larvae. Chemosphere 2018, 200, 30-35. [CrossRef] [PubMed]

90. Ellis, L.D.; Seibert, J.; Soanes, K.H. Distinct models of induced hyperactivity in zebrafish larvae. Brain Res. 2012, 1449, 46-59. [CrossRef]

91. Asmonaite, G.; Boyer, S.; Souza, K.B.; Wassmur, B.; Sturve, J. Behavioural toxicity assessment of silver ions and nanoparticles on zebrafish using a locomotion profiling approach. Aquat. Toxicol. (Amsterdam) 2016, 173, 143-153. [CrossRef] [PubMed]

92. Irons, T.D.; Kelly, P.E.; Hunter, D.L.; Macphail, R.C.; Padilla, S. Acute administration of dopaminergic drugs has differential effects on locomotion in larval zebrafish. Pharmacol. Biochem. Behav. 2013, 103, 792-813. [CrossRef] [PubMed]

93. Macaulay, L.J.; Bailey, J.M.; Levin, E.D.; Stapleton, H.M. Persisting effects of a pbde metabolite, 6-oh-bde-47, on larval and juvenile zebrafish swimming behavior. Neurotoxicol. Teratol. 2015, 52, 119-126. [CrossRef] [PubMed]

94. Colon-Cruz, L.; Kristofco, L.; Crooke-Rosado, J.; Acevedo, A.; Torrado, A.; Brooks, B.W.; Sosa, M.A.; Behra, M. Alterations of larval photo-dependent swimming responses (PDR): New endpoints for rapid and diagnostic screening of aquatic contamination. Ecotoxicol. Environ. Saf. 2018, 147, 670-680. [CrossRef] [PubMed]

95. Thit, A.; Skjolding, L.M.; Selck, H.; Sturve, J. Effects of copper oxide nanoparticles and copper ions to zebrafish (danio rerio) cells, embryos and fry. Toxicol. In Vitro Int. J. Publ. Assoc. BIBRA 2017, 45, 89-100. [CrossRef]

96. De Esch, C.; van der Linde, H.; Slieker, R.; Willemsen, R.; Wolterbeek, A.; Woutersen, R.; De Groot, D. Locomotor activity assay in zebrafish larvae: Influence of age, strain and ethanol. Neurotoxicol. Teratol. 2012, 34, 425-433. [CrossRef]

97. Ramcharitar, J.; Ibrahim, R.M. Ethanol modifies zebrafish responses to abrupt changes in light intensity. J. Clin. Neurosci. Off. J. Neurosurg. Soc. Australas. 2013, 20, 476-477. [CrossRef] [PubMed]

98. Dipp, V.R.; Valles, S.; Ortiz-Kerbertt, H.; Suarez, J.V.; Bardullas, U. Neurobehavioral alterations in zebrafish due to long-term exposure to low doses of inorganic arsenic. Zebrafish 2018, 15, 575-585. [CrossRef]

99. Li, F.; Lin, J.; Liu, X.; Li, W.; Ding, Y.; Zhang, Y.; Zhou, S.; Guo, N.; Li, Q. Characterization of the locomotor activities of zebrafish larvae under the influence of various neuroactive drugs. Ann. Transl. Med. 2018, 6, 173. [CrossRef] [PubMed]

100. Peng, X.; Lin, J.; Zhu, Y.; Liu, X.; Zhang, Y.; Ji, Y.; Yang, X.; Zhang, Y.; Guo, N.; Li, Q. Anxiety-related behavioral responses of pentylenetetrazole-treated zebrafish larvae to light-dark transitions. Pharmacol. Biochem. Behav. 2016, 145, 55-65. [CrossRef]

101. Spulber, S.; Kilian, P.; Wan Ibrahim, W.N.; Onishchenko, N.; Ulhaq, M.; Norrgren, L.; Negri, S.; Di Tuccio, M.; Ceccatelli, S. Pfos induces behavioral alterations, including spontaneous hyperactivity that is corrected by dexamfetamine in zebrafish larvae. PLoS ONE 2014, 9, e94227. [CrossRef]

102. Chen, X.; Huang, C.; Wang, X.; Chen, J.; Bai, C.; Chen, Y.; Chen, X.; Dong, Q.; Yang, D. Bde-47 disrupts axonal growth and motor behavior in developing zebrafish. Aquat. Toxicol. (Amsterdam) 2012, 120-121, 35-44. [CrossRef]

103. Liang, X.; Souders, C.L., 2nd; Zhang, J.; Martyniuk, C.J. Tributyltin induces premature hatching and reduces locomotor activity in zebrafish (danio rerio) embryos/larvae at environmentally relevant levels. Chemosphere 2017, 189, 498-506. [CrossRef]

104. Thompson, W.A.; Arnold, V.I.; Vijayan, M.M. Venlafaxine in embryos stimulates neurogenesis and disrupts larval behavior in zebrafish. Environ. Sci. Technol. 2017, 51, 12889-12897. [CrossRef] [PubMed] 
105. Goldstein, D.S. Adrenaline and noradrenaline. eLS 2010. [CrossRef]

106. Carter, K.M.; Woodley, C.M.; Brown, R.S. A review of tricaine methanesulfonate for anesthesia of fish. Rev. Fish Biol. Fish. 2010, 21, 51-59. [CrossRef]

107. Holdstock, L.; de Wit, H. Individual differences in the biphasic effects of ethanol. Alcohol. Clin. Exp. Res. 1998, 22, 1903-1911. [CrossRef]

108. Bremner, J.D.; Mletzko, T.; Welter, S.; Quinn, S.; Williams, C.; Brummer, M.; Siddiq, S.; Reed, L.; Heim, C.M.; Nemeroff, C.B. Effects of phenytoin on memory, cognition and brain structure in post-traumatic stress disorder: A pilot study. J. Psychopharmacol. (Oxford) 2005, 19, 159-165. [CrossRef]

109. Hidaka, N.; Suemaru, K.; Li, B.; Araki, H. Effects of repeated electroconvulsive seizures on spontaneous alternation behavior and locomotor activity in rats. Biol. Pharm. Bull. 2008, 31, 1928-1932. [CrossRef]

110. Tonelli, D.A.; Pereira, M.; Siba, I.P.; Martynhak, B.J.; Correia, D.; Casarotto, P.C.; Biojone, C.; Guimaraes, F.S.; Joca, S.L.; Andreatini, R. The antimanic-like effect of phenytoin and carbamazepine on methylphenidate-induced hyperlocomotion: Role of voltage-gated sodium channels. Fundam. Clin. Pharmacol. 2013, 27, 650-655. [CrossRef]

111. Nalivaeva, N.N.; Belyaev, N.D.; Turner, A.J. Sodium valproate: An old drug with new roles. Trends Pharmacol. Sci. 2009, 30, 509-514. [CrossRef]

112. Bogi, E.; Belovicova, K.; Ujhazy, E.; Mach, M.; Koprdova, R.; Zilava, L.; Garafova, A.; Jezova, D.; Dubovicky, M. Perinatal exposure to venlafaxine leads to lower anxiety and depression-like behavior in the adult rat offspring. Behav. Pharmacol. 2018, 29, 445-452. [CrossRef] [PubMed]

113. Gill, J.S.; Jamwal, S.; Kumar, P.; Deshmukh, R. Sertraline and venlafaxine improves motor performance and neurobehavioral deficit in quinolinic acid induced huntington's like symptoms in rats: Possible neurotransmitters modulation. Pharmacol. Rep. 2017, 69, 306-313. [CrossRef] [PubMed]

114. Mora-Zamorano, F.X.; Svoboda, K.R.; Carvan, M.J., 3rd. The nicotine-evoked locomotor response: A behavioral paradigm for toxicity screening in zebrafish (danio rerio) embryos and eleutheroembryos exposed to methylmercury. PLoS ONE 2016, 11, e0154570. [CrossRef] [PubMed]

115. Goulet, S.; Dore, F.Y.; Mirault, M.E. Neurobehavioral changes in mice chronically exposed to methylmercury during fetal and early postnatal development. Neurotoxicol. Teratol. 2003, 25, 335-347. [CrossRef]

116. Onishchenko, N.; Tamm, C.; Vahter, M.; Hokfelt, T.; Johnson, J.A.; Johnson, D.A.; Ceccatelli, S. Developmental exposure to methylmercury alters learning and induces depression-like behavior in male mice. Toxicol. Sci. Off. J. Soc. Toxicol. 2007, 97, 428-437. [CrossRef] [PubMed]

117. Berto-Junior, C.; de Carvalho, D.P.; Soares, P.; Miranda-Alves, L. Tributyltin and zebrafish: Swimming in dangerous water. Front. Endocrinol. 2018, 9, 152. [CrossRef] [PubMed] 